РЕГИОНАЛЬНАЯ И МУНИЦИПАЛЬНАЯ ЭКОНОМИКА

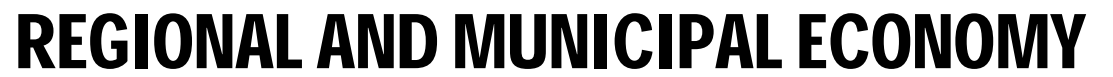

УДК 338

DOI 10.18413/2687-0932-2020-47-4-665-678

\title{
Формирование креативных центров в контексте развития социально-экономического потенциала сельских территорий: выявление и оценка лучших практик
}

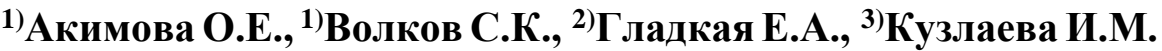 \\ 1) Волгоградский государственный технический университет \\ Россия, 400005, г. Волгоград, проспект Ленина, 28 \\ ${ }^{2)}$ Волгоградский государственный университет \\ Россия, 400062, г. Волгоград, проспект Университетский, 100 \\ 3) Ассоциация (некоммерческое партнерство) «Гарантийный фонд Волгоградской области» \\ Россия, 400012, г. Волгоград, проспект им. Маршала Советского Союза Г.К. Жукова, здание 3 \\ E-mail: akimovann25@mail.ru, ambiente2@rambler.ru, ras-umo@mail.ru,kmn07@mail.ru
}

\begin{abstract}
Аннотация
В рамках данной статьи рассмотрено влияние креативной составляющей на развитие сельских территорий и формирование креативных центров. Изучен вопрос развития инновационного общества знаний, развитие которого началось после информационной революции за счет выделения новых неограниченных ресурсов, таких как творческий потенциал и инновационное мышление, являющихся основными предпосылками развития креативной экономики. Креативный класс, составляющий одну из четырех категорий занятости, основанных на уникальных профессиональных группах, включает в себя людей, занятых в науке и технике, архитектуре и дизайне, образовании, искусстве, музыке и развлечениях. В статье идет речь о том, что благодаря креативному классу можно привлечь людей в сельскую местность, вопреки сложившейся тенденции оттока населения в города, а затем сформировать особое креативное пространство, которое сможет приносить финансовую выгоду экономике региона и развивать творческие способности граждан. Кроме того, рассмотрен опыт формирования подобных центров с целью выявления лучших практик. Однако в ходе исследования выяснилось, что в зарубежных странах в основном развитие креативной составляющей происходит через туристическую сферу, в Российской Федерации креативный класс в большей степени заинтересован крупными мегаполисами, а не сельскими территориями. Авторами был сделан вывод о том, что создание единой универсальной стратегии по развитию сельских территорий нецелесообразно, так как регион должен отслеживать и понимать открывающиеся возможности, связанные с креативным классом, прилагая по меньшей мере столько же усилий, сколько тратится на преднамеренное создание других возможностей.
\end{abstract}

Ключевые слова: сельские территории, креативные центры, креативный класс, креативная экономика.

Благодарности: исследование выполнено при финансовой поддержке РФФИ, проект № 20-010-00072 «Формирование креативных центров пространственного развития как механизм повышения качества жизни населения сельских территорий».

Для цитирования: Акимова О.Е., Волков С.К., Гладкая Е.А., Кузлаева И.М. 2020. Формирование креативных центров в контексте развития социально-экономического потенциала сельских территорий: выявление и оценка лучших практик. Экономика. Информатика. 47 (4): 665-678. DOI 10.18413/2687-0932-2020-47-4-665-678. 


\title{
Formation of creative centers in the context of the development of the socio-economic potential of rural areas: identification and evaluation of best practices
}

\author{
1)Akimova O.E., ${ }^{1)}$ Volkov S.K., ${ }^{2)}$ Gladkaya E.A., ${ }^{3)}$ Kuzlaeva I.M. \\ 1) Volgograd State Technical University, Russia, 400005, Volgograd, Lenin Avenue, 28 \\ 2) Volgograd State University, Russia, 400062, Volgograd, University Avenue, 100 \\ 3) Association (non-profit partnership) «Guarantee Fund of the Volgograd region» \\ Russia, 400012, Volgograd, Zhukov Avenue, building 3 \\ E-mail: akimovann25@mail.ru, ambiente2@rambler.ru, ras-umo@mail.ru,kmn07@mail.ru
}

\begin{abstract}
The article refers to the fact that thanks to the creative class, you can attract people to the countryside, contrary to the prevailing trend of population outflow to cities, and then create a special creative space that can bring financial benefits to the region's economy and develop the creative abilities of citizens. In addition, the experience of the formation of such centers in order to identify best practices is considered. However, during the study it turned out that in foreign countries the development of the creative component mainly occurs through the tourism sector, in the Russian Federation the creative class is more interested in large megacities, rather than rural areas. The authors concluded that the creation of a single universal strategy for the development of rural territories is not advisable, since the region should monitor and understand the opportunities that are associated with the creative class, making at least as much effort as it takes to deliberately create other opportunities.
\end{abstract}

Keywords: rural territories, creative centers, creative class, creative economy.

Acknowledgements: the study was carried out with the financial support of the Russian Foundation for Basic Research, project No. 20-010-00072 "Formation of creative centers of spatial development as a mechanism for improving the quality of life of the population of rural areas".

For citation: Akimova O.E., Volkov S.K., Gladkaya E.A., Kuzlaeva I.M. 2020. Formation of creative centers in the context of the development of the socio-economic potential of rural areas: identification and evaluation of best practices. Economics. Information technologies. 47 (4): 665-678 (in Russian). DOI 10.18413/26870932-2020-47-4-665-678.

\section{Введение}

Творчество, знания и инновации могут стать главными движущими силами регионального экономического, социального и культурного развития. Тенденция к урбанизации на фоне «вымирания» сельских территорий, сложившаяся на территории Российской Федерации в последние десятилетия, формирует необходимость изучения вопроса по развитию сельских территорий нетрадиционными способами. В качестве одного из способов развития социально-экономического потенциала сельских территорий можно использовать привлечение креативного класса. Многие факторы, которые привлекают в города креативный класс (уникальные возможности культурного наследия, свобода самовыражения, толерантность к проявлениям творчества и т. д.) существуют в изобилии и/или могут быть развиты в рамках сельских территорий. Такие возможности зачастую менее очевидны в сельской местности или могут возникать спонтанно и требовать несколько больших первоначальных инвестиций. Однако следует учитывать, что привлечение и удержание талантов, а именно представителей креативного класса, в сельских районах могло бы стать решением проблемы их экономического оживления и обращения вспять тенденции к сокращению численности населения. 


\section{Методология исследования}

Для достижения поставленной цели и решения задач использовались диалектический и системный подходы, общенаучные методы ретроспективного, ситуационного, компаративного, факторного анализа, контент-анализ научной литературы, экономико-статистический, сравнительный, аналитические методы исследования. Исследовательский подход основан на сравнении зарубежных примеров успешного создания креативных центров в сельской местности и опыта реализации концепции креативного роста в российской реальности.

\section{Теоретическая основа исследования}

Термин «креативная экономика» был впервые употреблен в журнале Business Week в 2000 году в контексте проведенного Национального инновационного саммита в Вашингтоне, где подчеркивалась необходимость создания общественных пространств для исследований, мышления и экспериментов, которые редко сами приходят с прибыльными продуктами в течение одного, двух или даже пяти лет, но которые предлагают новые важные идеи и концепции для бизнеса, чтобы использовать их на рынке [The Creative Economy, 2000, p. 2].

В рамках экономической деятельности часто можно наблюдать разрыв между теоретическими и практическими исследованиями, особенно очевидным это становится в вопросах, касающихся креативной сферы. Ученые-теоретики, такие как Дж. Пек, Р.А. Бошма, М. Фритч, М. Донеган, Д. Друкер, Х. Гольдштейн, Н. Лоу и Э. Малиция [Peck, 2005; Donegan, Drucker, Goldstein et al, 2008; Boschma, Fritsch, 2009], склонны критически относиться к данному вопросу, в отличие от ученых практиков, которые позитивно относятся к вопросу реализации креативной составляющей в экономике. Поддержку теории на практике можно увидеть в ряде инициатив творческих городов зарубежных стран, описываемых Э. КарридХэлкетт, Элизабет и К. Столариком [Currid-Halkett, Stolarick, 2011].

При изучении современных подходов к экономическому развитию сельских районов Дж. К. Морган, В. Ламбе и А. Фрейер предложили использовать три стратегии для стимулирования экономического роста сельских общин [Morgan, Lambe, Freyer, 2009]:

1. Развитие местности.

2. Развитие предпринимательской активности.

3. Развитие творческих способностей и талантов.

Подходы, основанные на развитии местности, пытаются извлечь выгоду из различных местных особенностей, которые определяют конкретное место, включая культурное наследие и исторические традиции, а также природные ресурсы. По мнению Дж. Хопкинса и Т. Марсдена, такие маркетинговые стратегии часто реализуются через развитие туризма и используют образы мирной сельской местности, чтобы изобразить сельские общины как места, предлагающие подлинные впечатления и расслабляющие условия [Hopkins, 1998].

Предпринимательская активность широко признана важной составляющей роста динамичной экономики. С.М. Гертлер, Д.А. Вулф, Д. Гаркут, П. Маскелл, А. Мальмберг и К. Морган утверждают, что стратегии, акцентирующие внимание на важности подходов к экономическому развитию через развитие предпринимательства, предполагают, что необходимо поддерживать местных предпринимателей и зарождающиеся фирмы, поскольку эта деятельность создает локальную укорененность, которая способствует развитию и укреплению экономической деятельности [Gertler, Wolfe, Garkut, 2000; Maskell, Malmberg, 1999; Morgan, 1997].

Третья стратегия, которая будет рассмотрена в данной статье, заключается в получении выгод от развития творческих способностей и талантов в сельской местности в качестве одного из способов содействия непрерывному экономическому росту. Креативная экономика в сельской местности, как правило, основана на наличии искусства и культуры. Предполагается, что формирование креативных центров в рамках сельских территорий может базироваться на художественных талантах, ремесленничестве и передаче опыта заинтересованным в этом лицам. Однако следует понимать, что процессы, определяющие экономическое развитие сельских территорий, особенно когда речь заходит о выявлении 
новых возможностей и местных ресурсов, гораздо более сложны, чем предполагает стратегия, и требуют детальной проработки.

Сельские территории действительно имеют возможности для восстановления своей экономики и содействия дальнейшему процветанию. По мере того, как крупные мегаполисы становятся центрами успешной наукоемкой промышленности, они осознают важность творческих работников для подпитки двигателя экономического роста и процветания. Вместе эти творческие работники составляют креативный класс, одну из четырех категорий занятости, основанных на уникальных профессиональных группах, определенных Ричардом Флоридой [Florida, 2002]. Креативный класс включает в себя людей, занятых в науке и технике, архитектуре и дизайне, образовании, искусстве, музыке и развлечениях. Основная экономическая функция креативного класса - генерировать новые идеи, новые технологии и/или новое творческое содержание. Три другие категории занятости, совпадающие с креативным классом, - это класс обслуживания, рабочий класс и люди, занятые в рыболовстве, сельском хозяйстве и лесном хозяйстве. Флорида продвигает идею о том, что новые бизнесинвестиции привлекаются в места, которые демонстрируют богатую концентрацию людей из креативного класса. Эти люди (креативный класс), в свою очередь, тяготеют к местам, которые могут обеспечить повышенное чувство качества, имеют культурные и исторические традиции, возможности для отдыха и изобилие открытых природных ресурсов. По мнению Р. Флориды, в результате инвестиции и продвижение культурно-рекреационной экономики стали новой конкурентной стратегией в крупных столичных центрах. На самом деле сельские общины зачастую наделены обилием местных ресурсов, которые креативный класс считает привлекательными, и могут использовать данный принцип для собственного развития.

Исследования экономического развития, базирующегося на «креативном классе» P. Флориды [Florida, 2003], были в основном ориентированы на город и не изучали мнения практиков в сельской местности.

В отечественной литературе вопросы развития креативной индустрии, изучаемые Л.Р. Зотовой, Е.П. Молодовой, Н.А. Кавериной, А.И. Гретченко, А.А. Гретченко, затрагивают города, но не включают в себя сельские территории [Каверина, Гретченко, 2019; Зотова, 2015; Молодова, 2011]. Учитывая расхождение мнений о креативном классе и отсутствие исследований мнений среди сельских практиков, мы стремимся понять: как теория креативного класса применима в рамках развития сельских территорий.

\section{Результаты исследования}

Под «креативными центрами» в рамках данной статьи понимаются географические пространства, формирующиеся за счет совместных усилий органов власти, научнообразовательных организаций, местного населения, «креативного класса» и других заинтересованных сторон, реализующие возможность трансформации качества социальноэкономического положения выбранной местности за счет использования и развития материальных и нематериальных ресурсов.

Креативные центры являются неотъемлемой частью креативной экономики и креативного сообщества, получивших широкое распространение в начале XXI века для обозначения креативных индустрий, которые производят широкий спектр товаров и услуг, обеспечивают работой большое количество людей, используют цифровые технологии, зависят от инноваций и развиваются в основном в США и Западной Европе. Толчком к становлению инновационного общества знаний послужила информационная революция, выделив новые неограниченные ресурсы - творческий потенциал и инновационное мышление, являющиеся основными предпосылками развития креативной экономики. В сложившихся условиях она становится движущей силой не только для художников, музыкантов, актеров и прочих людей творческих профессий, но также и для обрабатывающей промышленности, бизнес-сообщества и менеджмента. Креативные подходы обеспечивают новые уникальные решения в условиях турбулентной экономической среды и жесткой конкуренции на рынке. Впервые понятие креативных индустрий было официально использовано в новой программе культурной политики Австралии «Креативная нация» (Creative Nation) [Creative Nation, 1994], которая, по 
сути, представляла собой экономическую политику, направленную на использование новых возможностей информационных и цифровых технологий в мировой культуре.

Согласно определению ЮНКТАД, креативная экономика - «это новая концепция, основанная на взаимодействии человеческого творчества, идей и интеллектуальной собственности, знаний и технологий, которая включает в себя рекламу, архитектуру, декоративно-прикладное искусство, дизайн, моду, кино, видео, фотографию, музыку, исполнительское искусство, издательское дело, исследования и разработки, программное обеспечение, компьютерные игры, электронные издания и телевидение/радио [Creative Nation, 2004]. Вместе они составляют важный источник как культурных, так и коммерческих ценностей. Основными направлениями развития креативной экономики и культурного капитала страны являются культурное наследие и исполнительское искусство, на рисунке 1 показаны элементы креативных индустрий [Образование и креативная индустрия, 2017].

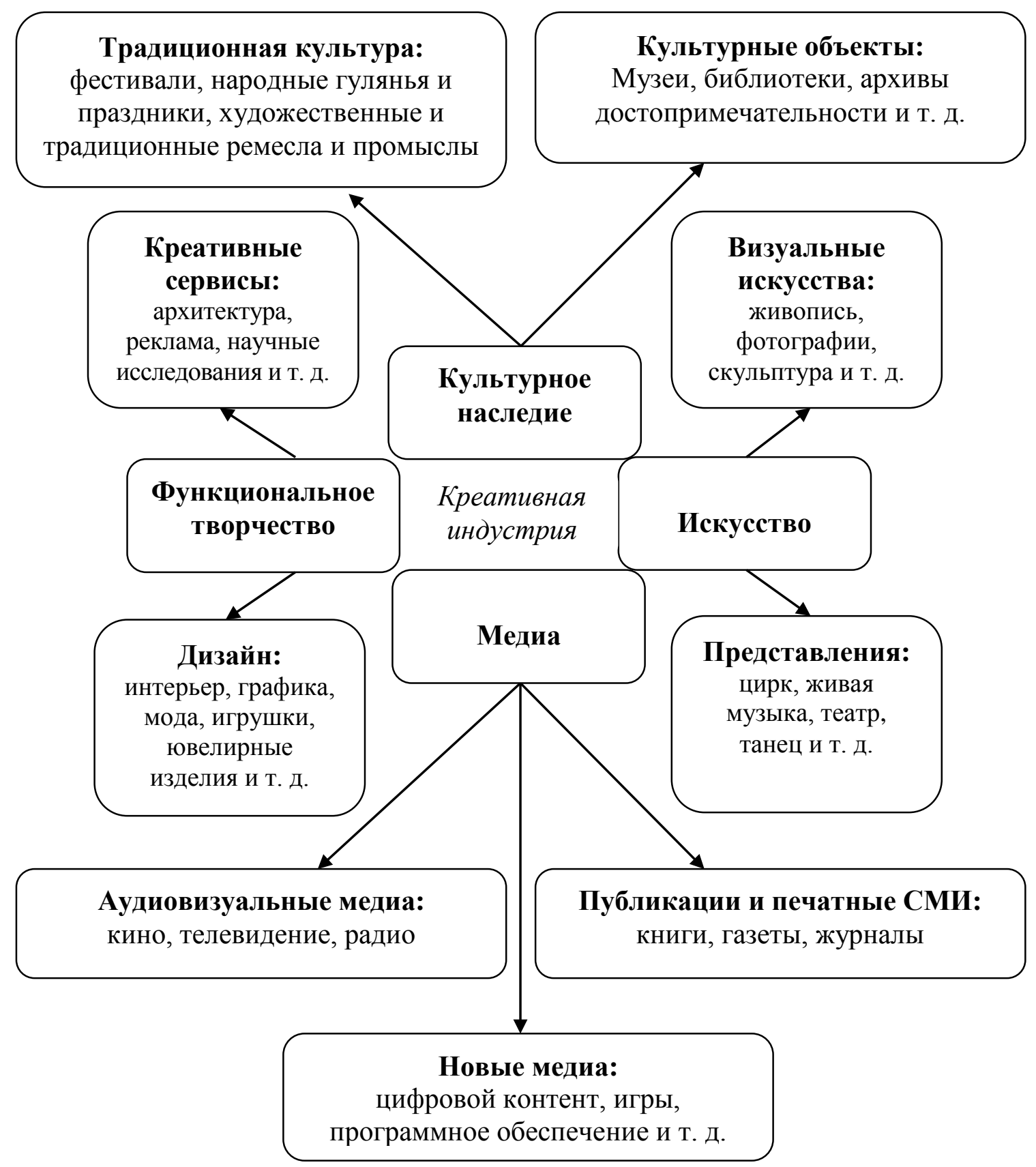

Рис. 1. Элементы креативной индустрии [Образование и креативная индустрия, 2017]

Fig. 1. Elements of the creative industry [Education and the creative industry, 2017] 
С точки зрения экономического содержания, креативные индустрии - это экономическая деятельность, основанная на использовании знаний, талантов и идей, воплощенных в бизнес-моделях и технологиях, для получения прибыли и раскрытия творческого потенциала. Креативные индустрии объединяют в себе процесс создания, производства и коммерциализации креативного контента, для которого присуща несущественная и культурная природа. Поскольку креативная экономика в наименьшей степени зависит от материальных ресурсов, она является наиболее динамичной с точки зрения создания рабочих мест, получения доходов и развития экспорта.

Объем международной торговли креативными товарами с 2002 по 2015 г. вырос более чем в 2 раза - с 436 млрд долларов до 964,1 млрд долларов (рис. 2), говорится в опубликованном в начале 2019 г. отчете Конференции ООН по торговле и развитию (ЮНКТАД) [Creative Economy, 2004]. К креативной экономике ООН относит модную индустрию, кинематограф, дизайн, рекламные услуги, ремесла, музыку и другие отрасли, основанные на интеллектуальной деятельности.

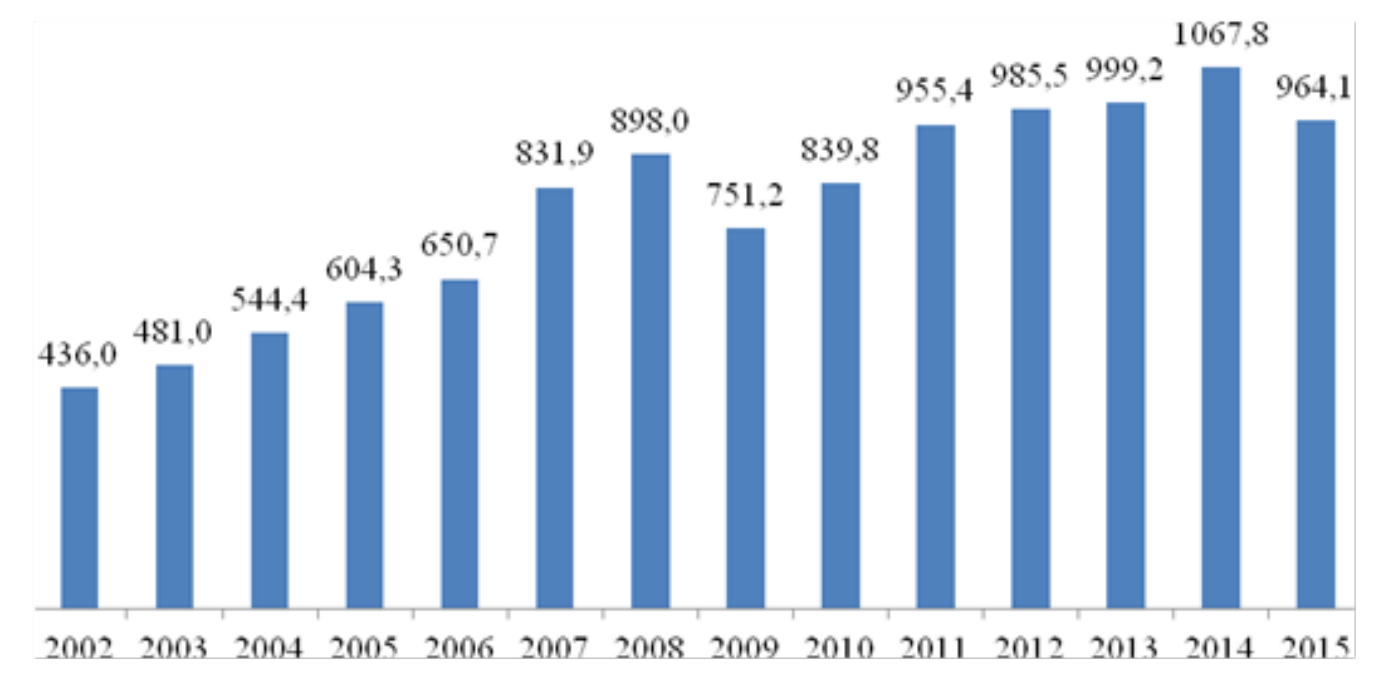

Рис. 2. Объем международной торговли креативными товарами, млрд долл. [Creative Economy, 2019]

Fig. 2. The volume of international trade in creative goods, billion dollars [Creative Economy, 2019]

В развитых странах доля креативных индустрий в ВВП может составлять до $9 \%$, в России вклад креативных индустрий в экономику оценивается по-разному: университет креативных индустрий Universal University оценивает этот вклад (без учета IT) как 0,5 \% российского ВВП (т. е. около 500 млрд руб., если исходить из оценки Росстата); InforMedia почти в 3 трлн руб. в 2018 г. (с учетом изобразительного искусства, СМИ, издательств, ТВ, интернет-рекламы, туризма, видеоигр и т. д. - коммерческих доходов и бюджетных средств) [Охлопкова, 2019]. Причина, главным образом, кроется в том, что понятие «креативная индустрия» не закреплено законодательно и у индустрий нет единого регулятора.

В мировой практике существуют яркие примеры того, как креативный класс может оказывать позитивное влияние на развитие сельских районов. Первым шагом на пути создания креативных центров в рамках сельских территорий становится креативный туризм.

В 2000 году Ричардс и Рэймонд представили то, что считается первым определением креативного туризма, описав его следующим образом: «туризм, который предлагает посетителям возможность развивать свой творческий потенциал посредством активного участия в учебных курсах и опыте, которые являются характеристиками места отдыха, где они находятся» [Richards, Raymond, 2000, p. 18]. Хотя за этим последовали и другие определения, это первоначальное определение продолжает служить краеугольным камнем в этой области. Растущий интерес к нематериальным элементам культуры вкупе с недовольством массовизацией традиционного культурного туризма породил спрос среди туристов на 
путешествия и направления, позволяющие им наслаждаться подлинным опытом, а также исследовать новые формы взаимодействия и социализации с людьми и местами, которые они посещают. Профиль туристов эволюционировал как все более осведомленный, информированный и требовательный.

Туристы посещают места для погружения в творческую среду и получения возможности заняться творческой деятельностью [Triarchi, Karamanis, 2017]. Однако творческий туризм подразумевает не только то, что туристы должны быть творчески вовлечены, но и то, что само место также должно стать более творческим для создания «характерных» впечатлений. Эволюционная связь между творчеством и туризмом заставляет нас переосмыслить важные аспекты современного туризма. Во-первых, туристы не только посещают места, но и создают их, и целью творческого туризма должно быть обеспечение обратной связи через обмен навыками и знаниями между местными жителями и теми, кто их посещает. Во-вторых, постепенное признание нематериальных элементов, таких как идентичность, образ жизни, традиции и т.д. акцентирует внимание на особенностях идентичности и соответствующих оценках активов для целей туризма. Исходя из этих факторов, мы утверждаем, что взаимодополняющие отношения между пространством и идентичностью должны стать краеугольным камнем для возникновения творческого туризма в сельских районах и небольших городах, уделяя особое внимание символическим измерениям местной культуры, которые люди развили в своих отношениях с этим пространством.

CREATOUR (Creative Tourism Destination Development in Small Cities and Rural Areas) - это национальный трехлетний научно-практический проект по разработке и экспериментальному внедрению комплексного подхода к развитию креативного туризма в малых городах и сельских районах Португалии, проходивший с 2017 по 2019 годы и состоявший из 40 пилотных проектов креативного туризма, 20 из которых были отобраны в 2017 году и 20 - в 2018 году [Duxbury, Silva, 2018]. Видение креативного туризма, направленного на пилотную деятельность CREATOUR, сосредоточено на активной творческой деятельности, поощряющей личное самовыражение и взаимодействие между посетителями и местными жителями, вдохновленное местными эндогенными ресурсами (местом и людьми), а также разработанное и реализованное местными жителями. Рабочее определение креативного туризма было принято как устойчивого мелкомасштабного туризма, который обеспечивает подлинный опыт посетителей, сочетая погружение в местную культуру с учебным и творческим процессом.

В контексте повышенного туристического спроса на посещение крупных городов и прибрежных курортных зон Португалии, CREATOUR направлен на развитие привлекательности предложения в менее посещаемых районах, а именно сельских районах и небольших городах. CREATOUR продвигает маломасштабную, интерактивную творческую туристическую деятельность, основанную на местных культурных традициях, навыках, знаниях и новых художественных практиках. Этот проект направлен на содействие устойчивому развитию местных общин, в том числе с финансовой точки зрения, по всей Португалии, а также поощряет (и будет контролировать) более широкое воздействие пилотных проектов в области креативного туризма на общины. Следует отметить, что среди этих пилотных проектов ведущую роль сыграли муниципалитеты, Ассоциации регионального развития и несколько частных предпринимателей, которые создали и координировали местные сети креативных туристических предложений в сотрудничестве с целым рядом независимых операторов.

Другие организационные модели включали интеграцию творческой деятельности как определяющей черты малых фестивалей; и традиционные предприятия, включающие творческий туризм и другие виды деятельности. В целом CREATOUR делает сильный акцент на месте, которое функционирует на нескольких уровнях: местные жители руководят проектированием и разработкой пилотных мероприятий, участие местного сообщества в этих 
мероприятиях настоятельно поощряется, а значительные и «особые» природные и исторические места обеспечивают некоторые контекстуализирующие места для проведения мероприятий. Все пилотные проекты разрабатывали и предлагали творческие туристические мероприятия, которые воплощают местные традиции или опыт, местную историю и образ жизни, смешанные с другими особенностями культурного и местного ландшафта тех мест, где были организованы мероприятия, будь то в небольшом городе или сельской местности. Этот чувствительный к месту процесс развития служил для соединения творчества с местом и создания подлинного, захватывающего и творческого опыта. Благодаря такому творческому опыту посетители получают возможность поближе познакомиться с местом назначения и его сообществом с точки зрения его истории, культуры, традиций, людей и историй, а затем использовать эти знания в качестве сырья или вдохновения для процессов творения и самовыражения.

Красочным примером построения креативного пространства, оказывающим непосредственное влияние на экономическое развитие и стимулирование сельскохозяйственных территорий, является расположенный на озере Онтарио округ Принц Эдуард, на сайте которого сказано, что это «прекрасное островное приключение, округ - это Мекка для художников, любителей природы и всех, кто ищет красивое островное приключение ... на выходные или на всю жизнь. Известный своими парусными прогулками, рыбной ловлей и гигантскими песчаными дюнами, этот округ также предлагает живой театр, студии художников и галереи, уникальную региональную кухню и процветающий винодельческий регион» [Prince Edward Country, 2020]. Графство Принц Эдуард является выдающимся примером сельской общины, которая использует свои природные ресурсы с акцентом на креативную экономику, включая гастрономию, этнологию, культуру и наследие, а также изобразительное искусство для создания не только желательного туристического направления, но и динамичного регионального экономического развития.

За период запуска проекта по развитию креативной составляющей графство Принц Эдуард добилось значительных успехов в привлечении творческих и хорошо образованных работников. В 1996 году этот округ не сильно выделялся среди других сельских районов Онтарио. Однако к 2006 году ему удалось отделиться, переключив свою экономику на более творческую занятость.

Построение успешных стратегий экономического развития в сельских общинах означает реализацию многочисленных способов взаимодействия различных частей экономики для создания новых возможностей и стимулирования роста. Согласно Блейкли и Брэдшоу, местное экономическое развитие - это попытка сообщества обеспечить рост путем мобилизации своего местного потенциала, включая его экономический, социальный, технологический и политический потенциал, а также свои ресурсы, включая наличие природных ресурсов, местоположение, рабочую силу, капитал, предпринимательский климат, инфраструктуру и промышленный состав. Выполнение такой задачи в сельских общинах может быть сложной задачей по многим причинам. Во-первых, региональные активы и потенциальные возможности, как правило, рассредоточены на большой территории в сельских общинах, и по этой причине их можно легко упустить или никогда не реализовать. Когда ресурсы распределены по таким обширным территориям, также может быть трудно понять, как они связаны или могут быть использованы вместе для создания новых и успешных экономических возможностей и предприятий. Во-вторых, поскольку сельские общины, как правило, имеют меньший размер, они также сталкиваются с проблемой объединения и генерирования различных видов капитала, необходимых для инвестирования в различные стратегии, новые предприятия и возможности. В совокупности эти проблемы, с которыми сталкиваются сельские общины при создании экономической активности, являются результатом трудностей, с которыми они сталкиваются при создании потенциала местных общин, что является важной характеристикой преодоления экономической неопределенности. Наконец, истории успеха в других сообществах очень далеки и немногочисленны. Это не 
означает, что они не существуют, но что они не могут быть задокументированы или легко переносимы в аналогичные стратегии в других регионах. Как и их гораздо более крупные городские аналоги, сельские общины не являются однородными, а это означает, что политика и стратегии экономического развития могут не давать одинаковых результатов во всех общинах. Хотя некоторые ресурсы и активы могут быть одинаковыми от одного сообщества к другому, контекст, в котором они находятся, может быть различным, и то, как они продаются и развиваются, может потребовать существенно различных подходов.

Для того, чтобы реализовать новые возможности в сельских общинах для содействия экономическому развитию, местные жители могут выступать в качестве интегративных мыслителей и реализовывать ответы, которые еще не были рассмотрены. Интегративное мышление - это процесс, посредством которого мы сортируем две или более, иногда конфликтующих, проблем в нашем уме, чтобы выработать единое превосходное решение. Это решение, достигнутое с помощью интегративного мышления, является не просто результатом быстрого выбора и принятия того или иного решения, но также требует понимания того, как работают проблемы, чтобы произвести синтез всех возможных решений, которые лучше, чем любое другое решение само по себе. В сельских общинах такое мышление является неотъемлемой частью работы над проблемами и поиска решений, особенно в плане признания нереализованных возможностей для содействия экономическому развитию.

Наконец, важность укрепления потенциала общин в сельских общинах проистекает из важности гибкого реагирования на внезапные запланированные или незапланированные события. Реагирование на такие события может дать сельским общинам новые возможности для содействия местному экономическому развитию. Однако, хотя наращивание потенциала общин является важным компонентом выявления возможностей и преодоления экономической неопределенности, достижение такого потенциала является регулярной задачей, стоящей перед сельскими общинами. Особенно важно, учитывая, что местные общины часто несут ответственность за инициирование местных инициатив в области экономического развития, создание потенциала направлено на создание организационного опыта путем формирования новых навыков в сельских общинах, связанных с лидерством, посредничеством и разрешением конфликтов, групповыми процессами, пониманием бизнеса правительства, а также формулированием и достижением общего видения

Традиционно в России креативный центр (пространство) носит урбанистический характер и понимается как публичное место, где все желающие могут выразить свои творческие порывы, поделиться опытом и получить возможность для самореализации. Это связано с тем, что в нашей стране креативный класс склонен к переезду в крупные города, где имеет место толерантность к проявлениям творчества, свобода самовыражения и открыт доступ к культурному наследию. В рамках исследования было выявлено, что в России до сих пор нет позитивных примеров создания креативных центров. В данной связи, основываясь на зарубежном опыте, мы предлагаем алгоритм по привлечению креативного класса и созданию с его помощью креативных центров в рамках сельскохозяйственных территорий.

В книге Ричард Флорида [Florida, 2002] утверждает, что сообщества с большим количеством людей, вовлеченных в искусство и другие творческие профессии (такие как учителя, архитекторы, компьютерные инженеры и т. д.) с большей вероятностью будут экономически процветающими по сравнению с общинами с более традиционной рабочей силой. Творчество, связанное с креативными профессиями, приводит к большему количеству инноваций в экономике. Поэтому местные органы власти должны проводить политику, связанную с привлечением и развитием креативного класса. Территории, поощряющие творчество, расовую и социальную терпимость, финансирующие развитие искусства и культуры становятся экономически устойчивыми и способствуют технологическому прогрессу. Такая стимулирующая политика развития является более эффективной, чем традиционная политика развития, например, привлечение бизнеса путем предоставления налоговых льгот. 
В рамках российской действительности необходимо следующее:

1. Постановка задачи по повсеместному развитию сельских территорий.

2. Объявление конкурса пилотных проектов.

3. Отбор проектов, наиболее удовлетворяющих условиям:

а) культурная ценность предлагаемых мероприятий;

б) творческий характер предлагаемых мероприятий;

в) потенциал туристической привлекательности;

г) влияние проекта на развитие местного сообщества;

д) разнообразие направленности предложений.

4. Запуск проектов: важно, чтобы проекты реализовывались как офлайн, так и онлайн. Онлайн реализация позволит привлечь больше людей через вебинары, уроки, веб-сайт.

5. Проекты должны взаимодополнять друг друга, с разных сторон раскрывая сущность и потенциал территории.

6. В проект должны быть вовлечены местные жители. развития.

7. Контроль и корректировка действий пилотных проектов на начальных этапах их

Творческий туризм является побочным видом деятельности для пилотных организаций, особенно на этих начальных этапах - такая ситуация означает, что сторонники пилотных мероприятий не имеют «идеальных условий», в которых можно было бы полностью сосредоточиться на этих инициативах. Прагматически это означает, что количество времени и усилий, которые они могут посвятить фоновым исследованиям, разработкам и планированию, ограничено. Это важнейшее условие, сдерживающее темпы развития пилотных проектов, а также фактор, который необходимо учитывать при разработке совместных исследовательских мероприятий.

Сделать деятельность экономически устойчивой - для большинства пилотов разработка и предложение творческих туристических семинаров и связанных с ними мероприятий является новым предприятием. Учитывая характер обучения путем экспериментирования в рамках проекта, реализация предложений осуществляется таким образом, что реализуемые бизнес-модели, возможно, сочетающие творческий туризм с другими видами деятельности, разрабатываются на основе самой практики. Для некоторых пилотов может потребоваться дальнейшее наставничество по проектам и поддержка бизнеспланирования. Необходимо учитывать две особенности: с одной стороны, существует недостаток всесторонне исследованных, успешных творческих бизнес-моделей креативного туризма на международном уровне; с другой стороны, масштаб каждой деятельности по своей природе ограничен, поэтому цель становится следующей: иметь достаточное количество посетителей для экономической устойчивости, но не слишком обременять сообщество.

\section{Заключение}

Экономическое развитие сельских районов - это сложная задача. Достижение успеха затруднительно, когда сельское хозяйство и обрабатывающая промышленность находятся в упадке, а молодежь, рабочая сила и новые фирмы, как представляется, почти исключительно тяготеют к более крупным городским районам. Для преодоления этих трудностей было предложено множество стратегий. К числу наиболее успешных относятся стратегии, основанные на туризме, которые используют природные, исторические и культурные ресурсы региона для развития и распространения опыта, обычно недоступного городским жителям. Однако стратегии, основанные на туризме, привносят новые структурные недостатки в экономику. Большинство рабочих мест, основанных на туризме (многие из них в сфере размещения и питания), являются низкооплачиваемыми и сезонными, не предлагают эквивалентной занятости потерянным производственным и сельскохозяйственным рабочим местам и увеличивают неравенство во всем регионе. 
Одним из способов преодоления этой трудности является не сосредоточение внимания на туризме как конечной желаемой экономической базе, а использование туризма и региональных удобств и качественных характеристик мест, необходимых для привлечения туристов, а также для привлечения жителей. В частности, стратегии, ориентированные на привлечение креативного класса в регион, могут дополнительно использовать региональные удобства для привлечения новых жителей и их семей в регион. Работники креативного класса имеют более высокий средний заработок, чем работники рабочего класса (обрабатывающей промышленности и строительства), класса обслуживания или сельского хозяйства. Творческие работники - это те, кто генерирует инновации, новые идеи и открывает новые предприятия. Концентрация творческих работников также может способствовать привлечению фирм в регион. Эта стратегия не приходит без своих собственных проблем. Неравенство в оплате труда может усугубляться увеличением числа творческих работников. Кроме того, могут возникнуть и другие проблемы, и трения, поскольку новые жители с другими приоритетами и желаниями интегрируются в существующее сообщество с давними устоявшимися нормами и традициями. Однако, как показывает пример округа Принц Эдуард, подход к привлечению туристов и местных жителей открывает потенциал для достижения успеха в экономическом развитии сельских районов.

Привлечение креативного класса в регион требует большего, чем просто быть хорошим туристическим направлением. В то время как туристические достопримечательности могут привлечь их в регион на выходные, необходимо больше, чтобы превратить их в постоянных жителей. Важно сосредоточить туристические возможности и региональные удобства вокруг природных, исторических и культурных ценностей, которые представляют собой подлинный опыт, который обычно желателен для представителей креативного класса. Но этого недостаточно; привлечение новых жителей и их семей также означает, что необходимо решить проблему качества жизни. По-прежнему необходимо уделять внимание качеству образования, здравоохранения и общей инфраструктуры территории. Сельские районы с большей вероятностью привлекут семьи, людей среднего возраста, меняющих профессию, и пенсионеров, которые ценят эти местные особенности так же высоко, как и другие удобства, которые изначально привели их в этот регион.

Креативный класс - это неоднородная группа, в которой все имеют совершенно одинаковые потребности и желания. В то время как некоторые характеристики обычно являются общими, люди и семьи движимы своим собственным уникальным сочетанием удобств, возможностей и опыта, которые будут привлекать их в регион. В результате любой регион - но особенно сельский регион с ограниченными возможностями обеспечения качества жизни - должен быть готов проявлять гибкость в разработке стратегий привлечения и реагирования на происходящие события. Вместо того чтобы пытаться построить всеобъемлющую целенаправленную стратегию, ориентированную на определенный сегмент креативного класса, регион должен сначала попытаться быть универсалистом, но тщательно отслеживать и затем реагировать на случайные события. Если один или два инженера впервые переезжают в регион, нужно уделить им внимание, чтобы помочь и поддержать их, а также необходимо работать над созданием кластера инженерного консалтинга. Однако если кто-то из новых резидентов занимается цифровыми медиа, то основное внимание должно быть уделено инфраструктуре широкополосного интернета и созданию цифрового медиакластера. Регион должен отслеживать и понимать открывающиеся возможности, прилагая по меньшей мере столько же усилий, сколько тратится на преднамеренное создание других возможностей.

Таким образом, для создания долговременных преимуществ для сельских районов необходимо использовать туризм не как самоцель, а как часть более широкой стратегии, направленной на повышение качества места, необходимого для того, чтобы стать не только туристическим направлением, но и повысить качество жизни в регионе. Эта двуединая стратегия привлечет в регион не только туристов, но и новых постоянных жителей и приведет к более устойчивому экономическому результату. 


\section{Список литературы}

1. Зотова Л.Р. 2015. Креативный город: творческие индустрии и развитие городов. Креативная экономика, 11. URL: https://cyberleninka.ru/article/n/kreativnyy-gorod-tvorcheskie-industrii-i-razvitiegorodov (дата обращения: 05.04.2020).

2. Каверина Н.А., Гретченко А.И., Гретченко А.А. 2019. Современное развитие креативных индустрий в России (опыт столицы и регионов). Вестник Саратовского государственного социальноэкономического университета, 1 (75). URL: https://cyberleninka.ru/article/n/sovremennoe-razvitiekreativnyh-industriy-v-rossii-opyt-stolitsy-i-regionov (дата обращения: 15.04.2020).

3. Молодова Е.П. 2011. Творческие индустрии как фактор развития территорий. Современные тенденции в экономике и управлении: новый взгляд, 11-1. URL: https://cyberleninka.ru/article/n/tvorcheskie-industrii-kak-faktor-razvitiya-territoriy (дата обращения: 11.04.2020).

4. Образование и креативная индустрия в зеркале международных и отечественных практик. 2017. Бюллетень о сфере образования. Аналитический центр при Правительстве Российской Федерации. URL: https://ac.gov.ru/files/publication/a/14525.pdf (дата обращения: 10.03.2020).

5. Охлопков А. Россия в центре креатива. Ведомости. 23 декабря 2019 URL: https://www.vedomosti.ru/partner/articles/2019/12/24/819475-rossiya-kreativa (дата обращения: 10.03.2020).

6. Boschma R. A., Fritsch M. 2009. Creative Class and Regional Growth: Empirical Evidence from Seven European Countries. Economic Geography, 85: 391-423.

7. Creative Economy Programme. United Nations Conference on Trade and Development. 2004. Available at: https://unctad.org/en/Pages/DITC/CreativeEconomy/Creative-Economy-Programme.aspx.

8. Creative Economy Programme. 2019. United Nations Conference on Trade and Development. Available at: https://unctad.org/en/Pages/DITC/CreativeEconomy/Creative-Economy-Programme.aspx.

9. Creative nation: Commonwealth cultural policy. 1994. Department of Communications and the Arts (Australia): $102 \mathrm{p}$.

10. Currid-Halkett E., Stolarick K. 2011. The Great Divide: Economic Development Theory Versus Practice - A Survey of the Current Landscape. Economic Development Quarterly, 25: 143-157.

11. Donegan M., Drucker J., Goldstein H., Lowe N., Malizia E. 2008. Which indicators explain metropolitan economic performance best? Traditional or creative class. Journal of the American Planning Association, 74 (2): 180-195.

12. Duxbury N., Silva S., Vinagre de Castro T. 2018. Creative tourism development in small cities and rural areas in Portugal: Insights from start-up activities. Creating and Managing Experiences in Cultural Tourism. World Scientific Publishing, 81-99.

13. Florida R. 2003. Cities and the Creative Class. City \& Community, 2: 3-19.

14. Florida R. 2003. The Rise of the Creative Class. New York: Basic Books, 237 p.

15. Florida, R. 2002.The Rise of the Creative Class: And How It's Transforming Work, Leisure, Community and Everyday, 253 p.

16. Gertler M. S., Wolfe D. A., Garkut D. 2000. No Place like Home? The Embeddedness of Innovation in a Regional Economy. Review of International Political Economy, 7(4): 688-718.

17. Hopkins J. 1998. Signs of the Post-Rural: Marketing Myths of a Symbolic Countryside. Geografiska Annaler, 80(2): 65-81.

18. Marsden T. 1999. Rural Futures: The Consumption Countryside and its Regulation. Sociologia Ruralis, 39(4): 501-520.

19. Maskell P., Malmberg A. 1999/ Localized learning and industrial competitiveness. Cambridge Journal of Economics, 23: 167-185

20. Morgan J. Q., Lambe W., Freyer A. 2009. Homegrown Responses to Economic Uncertainty in Rural America. Rural Realities, 3(2): 1-15.

21. Morgan K. 1997. The Learning Region: Institutions, Innovation and Regional Renewal. Regional Studies, 31(5): 491-503.

22. Peck J. 2005. Struggling with the Creative Class. International Journal of Urban and Regional Research, 29: 740-770.

23. Prince Edward County, Ontario. 2020. Available at: http://pecounty.on.ca.

24. Richards G., Raymond C. 2000. Creative tourism. ATLAS News, 23: 16-20.

25. The Creative Economy. 2000. Business Week, The 21st Century Corporation. August 28, 2000 (special double issue), August 28, 1-5.

26. Triarchi E., Karamanis K. 2017. Alternative tourism development: A theoretical background.

World Journal of Business and Management, 3 (1), 35 p. 


\section{References}

1. Zotova L.R. 2015. Kreativnyj gorod: tvorcheskie industrii i razvitie gorodov [Creative city: creative industries and urban development]. Kreativnaja jekonomika [Creative Economy], 11. URL: https://cyberleninka.ru/article/n/kreativnyy-gorod-tvorcheskie-industrii-i-razvitie-gorodov (accessed 04.04.2020).

2. Kaverina N.A., Gretchenko A.I., Gretchenko A.A. 2019. Sovremennoe razvitie kreativnyh industrij $\mathrm{v}$ Rossii (opyt stolicy i regionov) [Modern development of creative industries in Russia (experience of the capital and regions)]. Vestnik Saratovskogo gosudarstvennogo social'no-jekonomicheskogo universiteta. 1 (75). URL: https://cyberleninka.ru/article/n/sovremennoe-razvitie-kreativnyh-industriy-v-rossii-opyt-stolitsyi-regionov (дата обращения: 15.04.2020).

3. Molodova E. P. 2011. Tvorcheskie industrii kak faktor razvitija territorij [Creative industries as a factor in the development of territories]. Sovremennye tendencii v jekonomike i upravlenii: novyj vzgljad. 111. URL: https://cyberleninka.ru/article/n/tvorcheskie-industrii-kak-faktor-razvitiya-territoriy (дата обращения: 11.04.2020).

4. Obrazovanie i kreativnaja industrija $\mathrm{v}$ zerkale mezhdunarodnyh i otechestvennyh praktik [Education and the Creative Industry in the Mirror of International and Domestic Practices]. 2017. Bjulleten' o sfere obrazovanija. Analiticheskij centr pri Pravitel'stve Rossijskoj Federacii. URL: https://ac.gov.ru/files/publication/a/14525.pdf (дата обращения: 10.03.2020).

5. Ohlopkov A. 2019. Rossija v centre kreativa [Russia in the center of creativity]. Vedomosti. 23.12. URL: https://www.vedomosti.ru/partner/articles/2019/12/24/819475-rossiya-kreativa (дата обращения: 10.03.2020).

6. Boschma R. A., Fritsch M. 2009. Creative Class and Regional Growth: Empirical Evidence from Seven European Countries. Economic Geography, 85: 391-423.

7. Creative Economy Programme. United Nations Conference on Trade and Development. 2004. Available at: https://unctad.org/en/Pages/DITC/CreativeEconomy/Creative-Economy-Programme.aspx.

8. Creative Economy Programme. 2019. United Nations Conference on Trade and Development. Available at: https://unctad.org/en/Pages/DITC/CreativeEconomy/Creative-Economy-Programme.aspx.

9. Creative nation: Commonwealth cultural policy. 1994. Department of Communications and the Arts (Australia): $102 \mathrm{p}$.

10. Currid-Halkett E., Stolarick K. 2011. The Great Divide: Economic Development Theory Versus Practice - A Survey of the Current Landscape. Economic Development Quarterly, 25: 143-157.

11. Donegan M., Drucker J., Goldstein H., Lowe N., Malizia E. 2008. Which indicators explain metropolitan economic performance best? Traditional or creative class. Journal of the American Planning Association, 74 (2): 180-195.

12. Duxbury N., Silva S., Vinagre de Castro T. 2018. Creative tourism development in small cities and rural areas in Portugal: Insights from start-up activities. Creating and Managing Experiences in Cultural Tourism. World Scientific Publishing, 81-99.

13. Florida R. 2003. Cities and the Creative Class. City \& Community, 2: 3-19.

14. Florida R. 2003. The Rise of the Creative Class. New York: Basic Books, 237 p.

15. Florida, R. 2002.The Rise of the Creative Class: And How It's Transforming Work, Leisure, Community and Everyday, $253 \mathrm{p}$.

16. Gertler M. S., Wolfe D. A., Garkut D. 2000. No Place like Home? The Embeddedness of Innovation in a Regional Economy. Review of International Political Economy, 7(4): 688-718.

17. Hopkins J. 1998. Signs of the Post-Rural: Marketing Myths of a Symbolic Countryside. Geografiska Annaler, 80(2): 65-81.

18. Marsden T. 1999. Rural Futures: The Consumption Countryside and its Regulation. Sociologia Ruralis, 39(4): 501-520.

19. Maskell P., Malmberg A. 1999/ Localized learning and industrial competitiveness. Cambridge Journal of Economics, 23: 167-185

20. Morgan J. Q., Lambe W., Freyer A. 2009. Homegrown Responses to Economic Uncertainty in Rural America. Rural Realities, 3(2): 1-15.

21. Morgan K. 1997. The Learning Region: Institutions, Innovation and Regional Renewal. Regional Studies, 31(5): 491-503.

22. Peck J. 2005. Struggling with the Creative Class. International Journal of Urban and Regional Research, 29: 740-770.

23. Prince Edward County, Ontario. 2020. Available at: http://pecounty.on.ca. 
24. Richards G., Raymond C. 2000. Creative tourism. ATLAS News, 23: 16-20.

25. The Creative Economy. 2000. Business Week, The 21st Century Corporation. August 28, 2000 (special double issue), August 28, 1-5.

26. Triarchi E., Karamanis K. 2017. Alternative tourism development: A theoretical background. World Journal of Business and Management, 3 (1), 35 p.

\section{ИНФОРМАЦИЯ ОБ АВТОРАХ}

\begin{abstract}
Акимова Ольга Евгеньевна, кандидат экономических наук, доцент, доцент кафедры экономики и предпринимательства Волгоградского государственного технического университета, Волгоград, Россия
\end{abstract}

Волков Сергей Константинович, кандидат экономических наук, доцент, доцент кафедры экономики и предпринимательства Волгоградского государственного технического университета, Волгоград, Россия

Гладкая Елена Андреевна, кандидат экономических наук, ведущий специалист по работе с молодежью Волгоградского государственного университета, Волгоград, Россия

Кузлаева Ирина Михайловна, экономистменеджер Ассоциации (некоммерческое партнерство) «Гарантийный фонд Волгоградской области», Волгоград, Россия

\section{INFORMATION ABOUT THE AUTHORS}

Olga E. Akimova, Candidate of Economic Sciences, Associate professor, Associate professor of the Department of Economics and Entrepreneurship, Volgograd State Technical University, Volgograd, Russia

Sergey K. Volkov, Candidate of Economic Sciences, Associate professor, Associate professor of the Department of Economics and Entrepreneurship, Volgograd State Technical University, Volgograd, Russia

Elena A. Gladkaya, Candidate of Economic Sciences, leading specialist in youth work, Volgograd State University, Volgograd, Russia

Irina M. Kuzlaeva, economist-manager, Guarantee Fund of the Volgograd Region, Volgograd, Russia 